\title{
Acceleration of biodetoxification on dilute acid pretreated lignocellulose feedstock by aeration and the consequent ethanol fermentation evaluation
}

Yanqing He, Jian Zhang and Jie Bao*

\begin{abstract}
Background: Biodetoxification by the fungus Amorphotheca resinae ZN1 provides an effective way of inhibitor removal from pretreated lignocellulose feedstock and has been applied in the process of ethanol, biolipids, and lactic acid production. However, the long-time used and the consumption of considerable xylose in the pretreated materials reduced the process efficiency. The improvements of biodetoxification should be made to enhance the production of biochemical from lignocellulosic materials.

Results: This study reported an acceleration method of A. resinae ZN1-based biodetoxification on the corn stover (CS) feedstock pretreated using dry dilute acid pretreatment. Under proper aeration and well-mixing condition, the conversion rate of furfural, 5-hydroxymethylfurfural (HMF), acetic acid, and typical phenolic compounds were significantly accelerated by more than twofolds faster, which resulted in the reduction of biodetoxification time from $96 \mathrm{~h}$ in the conventional process to $36 \mathrm{~h}$. Simultaneous saccharification and ethanol fermentation assay on accelerated biodetoxification of the dry dilute acid pretreated CS feedstock achieved the similar ethanol titer $\left(48.56 \mathrm{~g} / \mathrm{L}\right.$ of $36 \mathrm{~h}^{\prime}$ accelerated biodetoxification vs. $50.00 \mathrm{~g} / \mathrm{L}$ of 4 days' conventional biodetoxification) and yield (58.10 vs. $59.63 \%$ ). Substrate priority of inhibitors to sugars by A. resinae ZN1 was discovered and considerable xylose was reserved in the accelerated biodetoxification. Cell growth of A. resinae fungus in liquid medium and on pretreated CS solids revealed that the enhanced aeration enhanced the biodetoxification rate rather than the cell growth rate. Accelerated inhibitor conversion might come from the increased supply of cofactors of nicotinamide adenine dinucleotide or nicotinamide adenine dinucleotide phosphate from the step of aldehyde inhibitors to the corresponding acids, instead of cell mass increase.
\end{abstract}

Conclusion: Accelerated biodetoxification reduced the period of biodetoxification and retained the xylose components in the pretreated CS, which provided a practical method on improving process efficiency for cellulosic ethanol production from severe pretreated lignocellulose feedstock.

Keywords: Biodetoxification, Inhibitors, Amorphotheca resinae ZN1, Aeration, Simultaneous saccharification and ethanol fermentation (SSF), Lignocellulose

\section{Background}

Pretreatment is the key step to overcome the biorecalcitrance of lignocellulose to obtain fermentable sugar

\footnotetext{
*Correspondence: jbao@ecust.edu.cn

State Key Laboratory of Bioreactor Engineering, East China University

of Science and Technology, 130 Meilong Road, 200237 Shanghai, China
}

formation in enzymatic hydrolysis step. During pretreatment processing, over-degradation of partial cellulose, hemicellulose, and lignin leads to the generation of various furan derivatives, organic acids, and phenolic compounds. These compounds severely inhibit consequent fermenting microbes [1]. Therefore, the removal of inhibitory compounds or "detoxification" is a prerequisite step 
for well growth and metabolism of fermenting strains to produce target biofuels and biochemicals. Available detoxification methods include water washing [2], overliming using $\mathrm{Ca}(\mathrm{OH})_{2}$ [3], ion-exchange, activated charcoal absorption [4], but these physical or chemical methods lead to the generation of huge waste water and loss of soluble sugars [5].

In recent few years, a new detoxification method using specific inhibitor degrading microorganisms demonstrated advantages of mild condition, low cost, high degradation efficiency, low energy consumption [6-9]. Various microorganisms have been isolated and applied to biodetoxification of inhibitors from pretreatment, including bacteria $[6,10-15]$, yeasts [16-18], and fungi [7, 19-24]. Among these studies, the fungus strain Amorphotheca resinae $\mathrm{ZN} 1$ performed biodetoxification on solid pretreated lignocellulose feedstock then applied to the consequent enzymatic hydrolysis and fermentation [7] for the production of ethanol [25], lipids [26], and lactic acid [27] with high product yield and zero waste water generation obtained. However, approximately 4-7 days of biodetoxification time and loss of xylose released from pretreatment are the two major technical barriers on reducing the overall process efficiency $[7,25]$.

In our previous study, the degradation of furfural and 5-hydroxymethylfurfural (HMF) in the synthetic medium by $A$. resinae $\mathrm{ZN} 1$ was improved when the constant aeration was kept during the culture. Thus this method was applied in the biodetoxification of pretreated corn stover (CS) to overcome the two drawbacks of biodetoxification method. Interestingly, the acceleration of biodetoxification of freshly pretreated CS material was realized by proper aeration and well-mixing approaches. Biodetoxification time was reduced from $96 \mathrm{~h}$ in the conventional biodetoxification to $36 \mathrm{~h}$ in the accelerated biodetoxification under the aeration rate of $1.00 \mathrm{vvm}$. Meanwhile, most of xylose released from dilute acid pretreatment was maintained during the shortened biodetoxification time because of the priority of inhibitor compounds to xylose by $A$. resinae $\mathrm{ZN} 1$. The present accelerated biodetoxification method provided an important solution for industrial application of biodetoxification approach in biorefining of lignocellulose for biofuels and biochemical production.

\section{Results and discussion}

\section{Biodegradation of inhibitors on solid pretreated CS by $A$. resinae $\mathrm{ZN} 1$}

Inhibitor degradation by $A$. resinae $\mathrm{ZN} 1$ has been investigated in synthetic medium [28, 29]. The detailed degradation in real pretreated lignocellulose materials has not yet completely profiled although the biodetoxification method had been applied in the pretreated materials such as CS, wheat straw, rape straw, and rice straw as described in [7]. In this study, the inhibitor conversion performance in the pretreated CS was examined. After the seed mycelia of $A$. resinae $\mathrm{ZN} 1$ was inoculated onto the pretreated CS, the major representative inhibitors in the pretreated CS were monitored during biodetoxification process (Fig. 1), including two furan aldehydes, furfural, and HMF; one weak acid, acetic acid; and three phenolic compounds, 4-hydroxybenzaldehyde representing $\mathrm{H}$ group of lignin compounds, syringaldehyde representing $S$ group, and vanillin representing $G$ group.

Furfural was quickly converted to the corresponding furfuryl alcohol, then to the potential intermediate furoic acid at low concentration and quickly consumed (Fig. 1a). HMF was converted to HMF alcohol (2,5-furandimethanol) and HMF acid (5-Hydroxymethyl-2-furoic acid) (Fig. 1b). The tendency of furfural and HMF was similar to that in the synthetic medium [28, 29]. The sum of furfural or HMF with their corresponding metabolites during biodetoxification was approximately in mass balance to the starting furfural or HMF. Approximately, the complete degradation of furfural took 3 days and HMF took 4 days for the pretreated CS material. Acetic acid completely degraded within 4 days with no secondary metabolites detected (Fig. 1c). The conversion rate of acetic acid was accelerated when furfural was reduced to low content at 2 days. The conversion of the three phenolic aldehydes shows that vanillin and syringaldehyde increased in the first 3 days and then quickly degraded to a low level, while the relatively low titer of 4-hydroxybenzaldehyde kept decreasing (Fig. 1d). The degradation rate of vanillin and syringaldehyde accelerated after the complete conversion of furfural at 3 days. The result suggests that the decrease of furfural to a certain point triggered the quick degradation of other inhibitors such as HMF, acetic acid, phenolic aldehydes. On the other hand, xylose consumption in the pretreated CS rate accelerated when furfural was completely removed: only $4.7 \mathrm{mg} / \mathrm{g}$ DM per day for xylose in the first 3 days, but reached $34 \mathrm{mg} / \mathrm{g}$ DM per day for xylose at 4th day and quickly consumed out in the next few days, indicating that furfural decrease also triggered the quick consumption of glucose and xylose. Based on the results, the complete removal time of furfural by $A$. resinae $\mathrm{ZN} 1$ was defined as the ending point of biodetoxification for the present pretreated CS material.

After the conventional biodetoxification, the CS feedstock was sent to simultaneous saccharification and ethanol fermentation (SSF) at $30 \%(w / w)$ solids content and $15 \mathrm{FPU} / \mathrm{g}$ DM cellulase dosage. Corn stover hydrolysate without biodetoxification treatment contained $0.75 \mathrm{~g} / \mathrm{L}$ of furfural, $0.53 \mathrm{~g} / \mathrm{L}$ of HMF, $0.57 \mathrm{~g} / \mathrm{L}$ of vanillin, and $0.26 \mathrm{~g} / \mathrm{L}$ of syringaldehyde, and the high inhibitor 

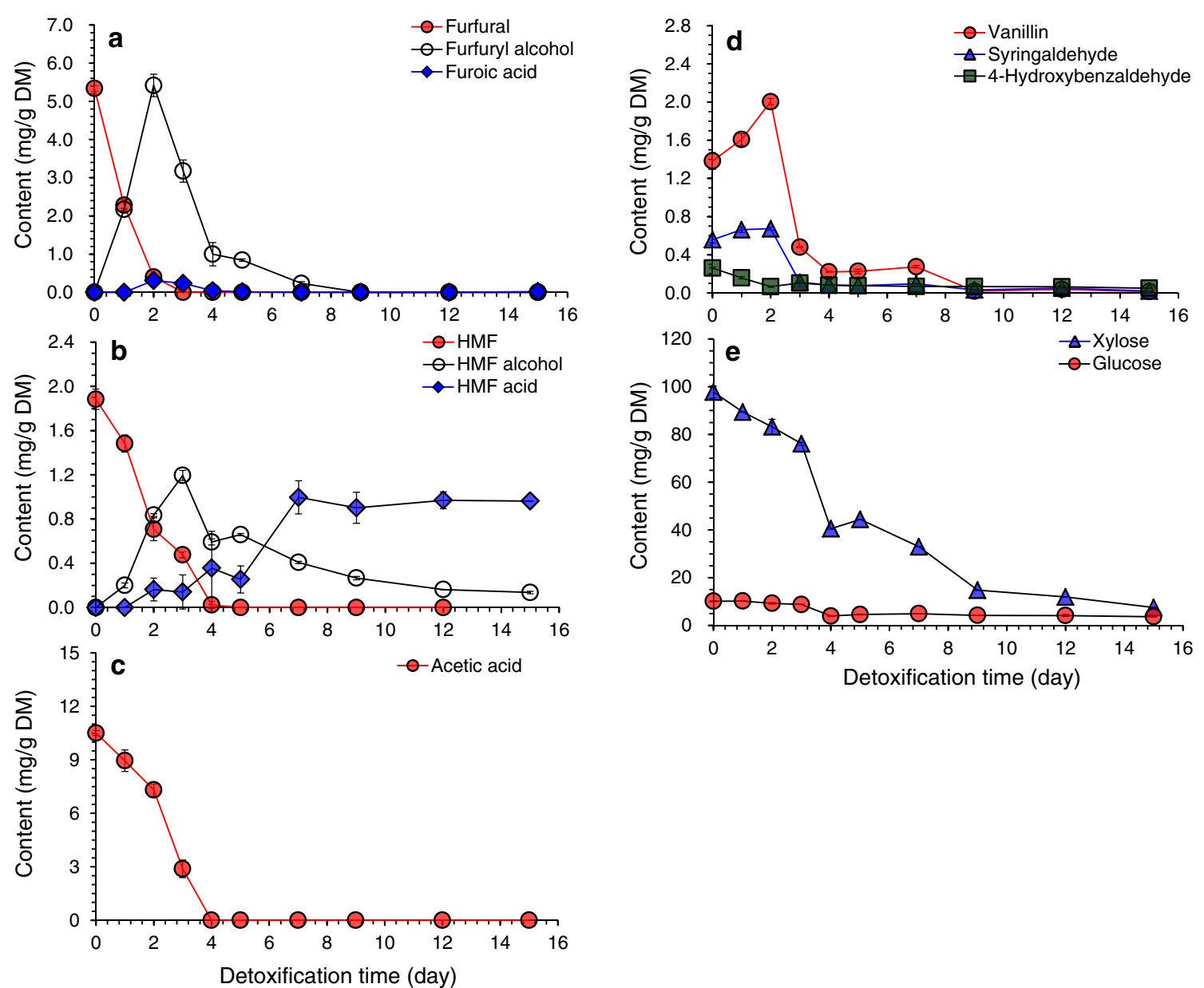

Fig. 1 Biodetoxification of dry dilute acid pretreated corn stover by A. resinae in conventional solid state mode. The biodetoxification was carried out in a plastic box with $2 \mathrm{~kg}$ pretreated corn stover loading at $28^{\circ} \mathrm{C}, \mathrm{pH} 5.5$, and $10 \%(\mathrm{~W} / \mathrm{W})$ inoculum of solid seed. a Furfural conversion; b HMF conversion; c Acetic acid conversion; d Phenolics conversion; e Sugars consumptions

content resulted in a low glucose generation in the $12 \mathrm{~h}$ ' pre-hydrolysis (41.99 $\mathrm{g} / \mathrm{L}$ of glucose) and ethanol titer in the SSF $(5.31 \mathrm{~g} / \mathrm{L})$ (Table 1$)$. After 1 day's detoxification, furfural was decreased to half of the original concentration $(0.35 \mathrm{~g} / \mathrm{L})$, the glucose concentration in the prehydrolysis (71.57 $\mathrm{g} / \mathrm{L}$ of glucose) and the ethanol titer in the SSF $(46.16 \mathrm{~g} / \mathrm{L})$ were significantly increased. As the biodetoxification time on pretreated CS feedstock prolonged, the glucose concentration in the pre-hydrolysis and the ethanol titer in the SSF increased correspondingly. Although the main inhibitors such as furans, acetic acid, and three phenolic compounds were degraded, the kinds of residual phenolic compounds were various and most of them were hard to separate from CS hydrolysate for detection. These compounds might be a potential inhibitor of cellulase. The prolonging of biodetoxification period decreased the level of these compounds leading to the increase of glucose concentration after pre-hydrolysis and ethanol titer. Four days' detoxification time led to the better fermentation performance on ethanol titer $(50.00 \mathrm{~g} / \mathrm{L})$ and ethanol productivity $(2.72 \mathrm{~g} / \mathrm{L} / \mathrm{h})$ but still $34 \%$ of xylose consumption after detoxification.

\section{Accelerated detoxification of $A$. resinae ZN1 under aeration and well-mixing conditions}

Aeration was found to accelerate the biodegradation rate of inhibitor compounds in liquid medium in our previous study [28]. In this study, aeration was applied to the conventional solid state biodetoxification of the CS prepared by dry dilute acid pretreatment in well-mixing bioreactor with helical ribbon stirrer agitator. The results in Figs. 2 and 3 show the accelerated degradation of furfural, HMF, and other inhibitors in the biodetoxification under the aeration rate of $0.33 \mathrm{vvm}$ compared to the batch without 
Table 1 Simultaneous saccharification and ethanol fermentation (SSF) using dry dilute acid pretreated and biodetoxified corn stover feedstock with changing biodetoxification time

\begin{tabular}{|c|c|c|c|c|c|c|c|c|c|c|c|}
\hline \multirow[t]{2}{*}{$\begin{array}{l}\text { Detoxification } \\
\text { time (day) }\end{array}$} & \multicolumn{6}{|c|}{ Inhibitors in hydrolysate (g/L) } & \multicolumn{2}{|c|}{$\begin{array}{l}\text { Sugars in hydro- } \\
\text { lysate }^{a}(g / L)\end{array}$} & \multirow[t]{2}{*}{$\begin{array}{l}\text { Ethanol titer } \\
(\mathrm{g} / \mathrm{L})\end{array}$} & \multirow{2}{*}{$\begin{array}{l}\text { Ethanol } \\
\text { productivity } \\
\text { (g/L/h) }\end{array}$} & \multirow[t]{2}{*}{$\begin{array}{l}\text { Ethanol yield } \\
\text { (\%) }\end{array}$} \\
\hline & Furfural & HMF & Acetate & Vanillin & 4-HBA & $\begin{array}{l}\text { Syringalde- } \\
\text { hyde }\end{array}$ & Glucose & Xylose & & & \\
\hline 0 & 0.75 & 0.53 & 6.16 & 0.57 & 0.06 & 0.25 & 41.99 & 44.65 & 5.31 & 0.39 & 5.97 \\
\hline 1 & 0.35 & 0.44 & 5.88 & 0.45 & 0.03 & 0.19 & 71.57 & 48.65 & 46.16 & 1.27 & 58.34 \\
\hline 2 & 0.16 & 0.24 & 4.99 & 0.22 & 0.02 & 0.06 & 71.52 & 45.19 & 46.85 & 1.60 & 57.08 \\
\hline 3 & 0.07 & 0.20 & 4.07 & 0.03 & 0.02 & 0.03 & 74.27 & 44.24 & 47.88 & 2.12 & 57.28 \\
\hline 4 & 0.00 & 0.00 & 1.28 & 0.09 & 0.02 & 0.05 & 81.13 & 29.58 & 50.00 & 2.72 & 59.63 \\
\hline 5 & 0.00 & 0.00 & 1.37 & 0.08 & 0.02 & 0.05 & 79.28 & 28.58 & 48.19 & 2.90 & 55.70 \\
\hline 7 & 0.00 & 0.00 & 1.35 & 0.08 & 0.02 & 0.06 & 82.47 & 23.07 & 51.07 & 2.62 & 57.29 \\
\hline 9 & 0.00 & 0.00 & 0.75 & 0.02 & 0.02 & 0.03 & 81.25 & 14.61 & 50.41 & 2.36 & 55.30 \\
\hline 12 & 0.00 & 0.00 & 1.63 & 0.02 & 0.01 & 0.03 & 83.01 & 10.49 & 52.33 & 2.66 & 57.30 \\
\hline 15 & 0.00 & 0.00 & 0.80 & 0.01 & 0.01 & 0.02 & 91.31 & 12.10 & 53.88 & 2.67 & 59.38 \\
\hline
\end{tabular}

SSF was initiated by pre-hydrolysis for $12 \mathrm{~h}$ and then the adapted S. cerevisiae DQ1 was inoculated into the hydrolysate at $10 \%$ inoculum to start SSF. SSF conditions: $30 \%$ solids loading, $15 \mathrm{FPU} / \mathrm{g}$ DM cellulase dosage, $150 \mathrm{rpm}$ agitation rate; Pre-hydrolysis was conducted at $50^{\circ} \mathrm{C}, \mathrm{pH} 4.8$, and SSF was conducted at $37^{\circ} \mathrm{C}$, pH 5.5 , respectively

a Glucose and xylose concentration were detected in the hydrolysate after $12 h^{\prime}$ enzymatic hydrolysis by cellulase

b Ethanol yield was calculated using the methods described by Zhang [41]

aeration in the fermenter, which indicated that the aeration was an effective way to improve the efficiency of biodetoxification by $A$. resinae $\mathrm{ZN} 1$. The conversion of furfural to furfuryl alcohol then to furoic acid was accelerated by increasing aeration rate in the range of $0.33-$ $1.33 \mathrm{vvm}$ (Fig. 2a-c). The conversion of HMF to HMF alcohol and HMF acid was accelerated only when furfural was reduced to the half of original content (Fig. 2d-f). Similar to HMF conversion, the conversions of acetic acid were accelerated when furfural was reduced to a low content (Fig. 3a). The content of vanillin and syringaldehyde increased a little and then quickly decreased when furfural had been completely removed (Fig. 3b, d), which was similar with the phenomenon described in Fig. 1d. Figure 4 showed that no obvious sugar (mainly xylose and minor glucose) consumption was detected in the batch without aeration, which was opposite to the results of the culture in plastic boxes during static biodetoxification. The sealed structure of fermenter made the detoxification process in an anaerobic environment, which the fungus $A$. resinae $\mathrm{ZN} 1$ stop the inhibitor degradation. Sugars did not really start to be consumed by $A$. resinae $\mathrm{ZN} 1$ when furfural was not completely converted even under the increasing aeration rate (Fig. 4). Most glucose in the first $24 \mathrm{~h}$ and most xylose in the first $48 \mathrm{~h}$ still remained unchanged until furfural was completely removed. In another word, glucose and xylose were reserved during the aerated biodetoxification period. The acceleration in the biodetoxification and reservation of sugars in the pretreated CS under aeration were similar to that in the synthetic medium described by Ran et al. [28]. Furthermore, the acceleration in the biodetoxification of pretreated CS was caused by the faster conversion furfural to furfuryl alcohol (Figs. 2 and 3), which indicated that the step-limiting step during biodetoxification under aeration was also the furfural conversion. As an ending indicator of biodetoxification, furfural was completely converted within $36 \mathrm{~h}$ at the aeration rate of $1.00 \mathrm{vvm}$ from $96 \mathrm{~h}$ of the non-aerated conventional biodetoxification.

Furfural as a volatile compound could be easily taken away under the constant aeration condition, which made it hard to evaluate if the improved detoxification was caused by the biological way of $A$. resinae ZN1. To further confirm the effect of detoxification by $A$. resinae $\mathrm{ZN} 1$, the control experiments using pretreated CS without inoculation of $A$. resinae $\mathrm{ZN} 1$ was carried out under different aeration as shown in Additional file 1: Figure S1. The volatilization of furfural was similar among the batch under the aeration rate of $0.33,0.50,0.67 \mathrm{vvm}$. The furfural content was reduced to $50 \%$ of the origin content under these three aeration rate after $36 \mathrm{~h}$. The increase of the furfural volatilization could be observed when the aeration rate was increased to 1.00 and $1.33 \mathrm{vvm}$, where about $70 \%$ of furfural was removed by aeration. However, there is no generation of furfuryl alcohol and furoic acid during the process. So was the degradation of HMF. These results were in accordance with that in the synthetic medium with single inhibitor addition described by Ran et al. [28]. As mentioned above, furfural 

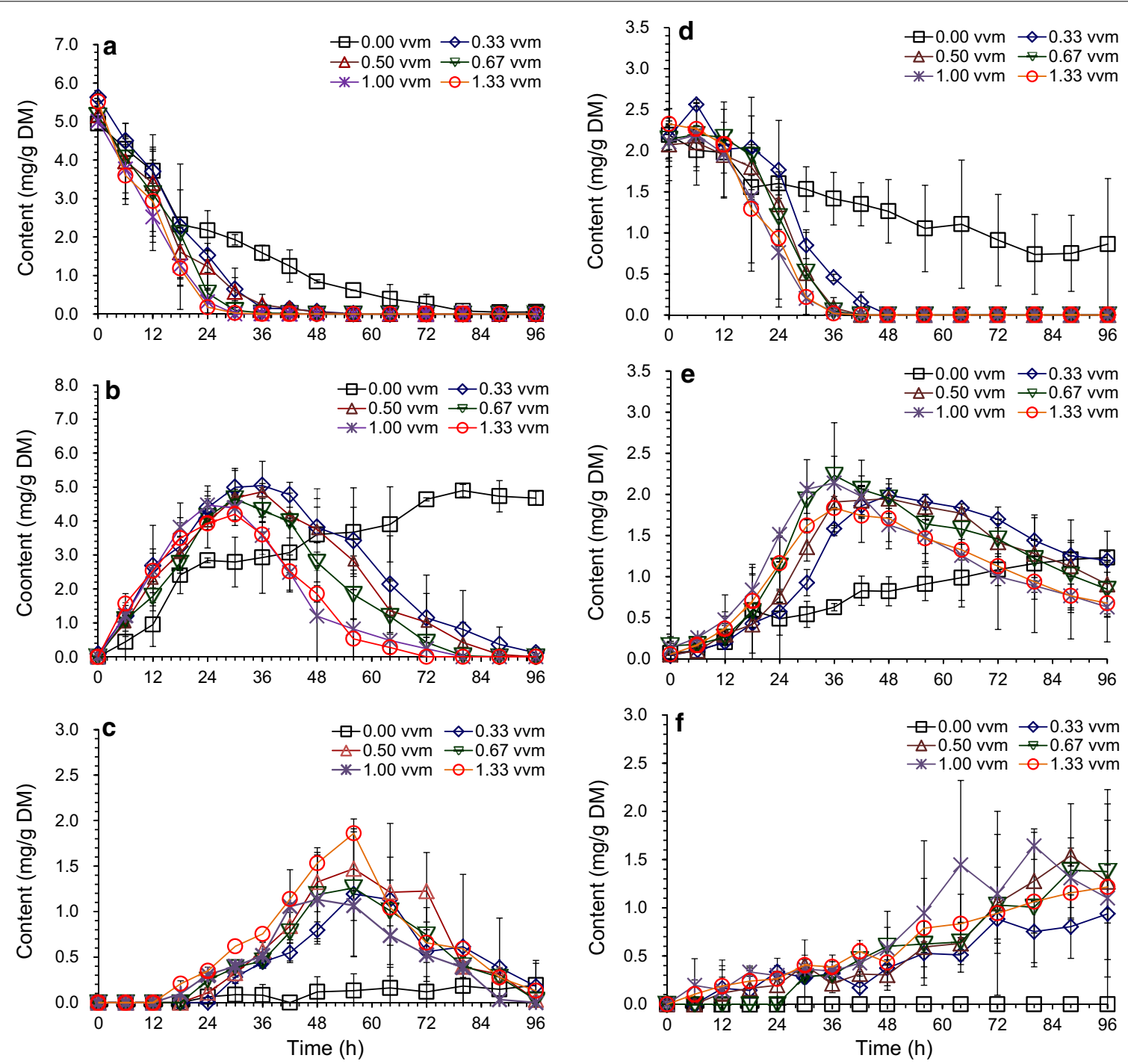

Fig. 2 Bioconversions of furfural and HMF on pretreated corn stover in aerated biodetoxification mode. Aeration rate was set to $0.00,0.33,0.50$, $0.67,1.00$, and $1.33 \mathrm{vvm}$ (defined as the air volumetric flowrate in liter per minute to the corn stover feedstock volume in liter). Biodetoxification conditions: $28^{\circ} \mathrm{C}, \mathrm{pH} 5.5,10 \%$ inoculum. a Furfural; b Furfuryl alcohol; c Furoic acid; d HMF; e HMF alcohol; $\mathbf{f H M F}$ acid

conversion was the first step for biodetoxification and the corresponding furfuryl alcohol and acid would be generated as the metabolites of furfural by A. resinae ZN1 in a corresponding concentration. Thus, the inhibitor degradation in the pretreated CS was due to the biological detoxification by $A$. resinae $\mathrm{ZN} 1$.

The consequent SSF using the aerated biodetoxified CS feedstock showed obvious advantage in ethanol titer, productivity, and glucose consumption rate over the conventionally detoxified feedstock (Fig. 5). At aeration rate of $1.00 \mathrm{vvm}$ for $36 \mathrm{~h}$, the ethanol titer of $48.56 \mathrm{~g} / \mathrm{L}$ and ethanol productivity of $2.07 \mathrm{~g} / \mathrm{L} / \mathrm{h}$ were similar to that under the conventional detoxification for $96 \mathrm{~h}$. Increased aeration rate from 0.33 to $1.33 \mathrm{vvm}$ gave approximately the same results, indicating that the minimum aeration rate was sufficient enough for aerated biodetoxification. Xylose concentration was still maintained at $40-50 \mathrm{~g} / \mathrm{L}$ using the aerated detoxified CS, comparing to only $10-20 \mathrm{~g} / \mathrm{L}$ of xylose in the conventional detoxification. The saved xylose could be used for producing more ethanol when xylose utilizing strain was used. Xylose maintaining from biodetoxification process made it possible for xylose extraction from ethanol broth. Moreover, the xylose maintaining makes the dry dilute acid pretreatment and biodetoxification applicable for the process of the products fermented by various xylose fermenting strains, which is meaningful for the biorefinery from lignocellulose in the future. Thus the accelerated biodetoxification by $A$. resinae $\mathrm{ZN} 1$ was defined as the fast inhibitor degradation process occurring on pretreated 

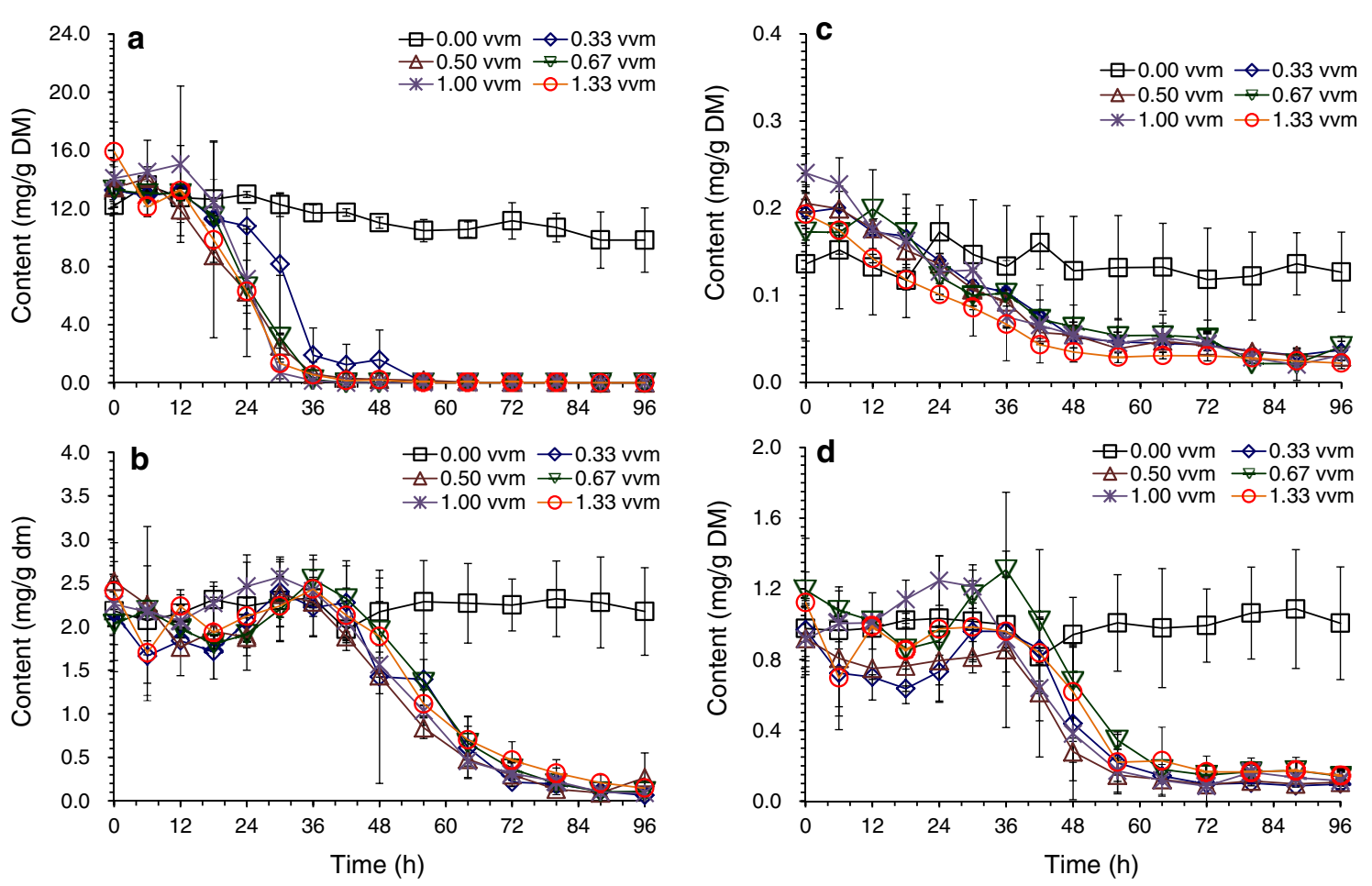

Fig. 3 Bioconversions of acetic acid and phenolic compounds on pretreated corn stover in aerated biodetoxification mode. Same biodetoxification conditions with Fig. 2. a Acetic acid; b Vanillin; c 4-Hydroxybenzaldehyde (4-HBA); d Syringaldehyde

lignocellulose feedstock by A. resinae ZN1 under proper aeration.

To examine the flexibility of aerated biodetoxification at different pretreatment severity, CS with additionally added furfural was regulated to generate a furfural gradient of 2.93, 7.32, 9.37, and $11.79 \mathrm{mg} / \mathrm{g} \mathrm{DM}$, then biodetoxified under aeration condition and sent to SSF. The conversion rate of furfural by $A$. resinae $\mathrm{ZN} 1$ was approximately the same at different furfural concentration, but the time used for complete consumption increased with increasing furfural concentration (Fig. 6a). Furfural was unable to be completely degraded when furfural was above $10 \mathrm{mg} / \mathrm{g}$ DM in the pretreated CS. Conversion of furfural to furfuryl alcohol and furoic acid was also inhibited by higher furfural content (Fig. 6b). Although HMF and acetic acid content were same to the control feedstock, high furfural also decreased their conversion rates (Fig. 6c-e). The SSF result shows that the ethanol titer, productivity, and glucose consumption rate were significantly affected when furfural content increased to about $10 \mathrm{mg} / \mathrm{g} \mathrm{DM}$ (Fig. 6f). When furfural was reduced to about $7.0 \mathrm{mg} / \mathrm{g}$ DM in the pretreated CS (equivalent to $6.0 \mathrm{~g} / \mathrm{L}$ in the hydrolysate), the $36 \mathrm{~h}$ ' aerated biodetoxification was still able to let SSF at a satisfactory performance. Compared to furfural tolerant stains Leuconostoc strains and Enterobacter cloacae GGT036 researched by Hunter et al. [13] and Choi et al. [15], A. resinae ZN1 possesses the stronger degradation capacity and higher tolerance to furfural, which made it capable to detoxify extensively pretreated lignocellulose feedstock. Besides the furfural adaption, $A$. resinae $\mathrm{ZN} 1$ also had a wide adaption on the inhibitors generated from pretreatment process. Compared to the biodetoxification by bacteria and yeast, the fungus had an advantage on the ability to degrade the various kinds of inhibitors generated in the pretreatment process due to the more complete metabolic pathway. The fungus Coniochaeta lignaria isolated by Nichols et al. [21] also showed great ability on various inhibitor degradation in the hydrolysate within $24 \mathrm{~h}$ with the aid of high rotation rate in the shaker. Compared to the research and application of Coniochaeta lignaria [20-23], A. resinae ZN1 could handle a much higher content of inhibitors in the solid CS with $50 \%$ water content, which removed the water wash and the separation of hydrolysate after pretreatment step. These properties made $A$. resinae $\mathrm{ZN} 1$ and accelerated biodetoxification step potential in the biorefinery process at a large scale or industrial production.

\section{Cell growth of $A$. resinae ZN1 during accelerated biodetoxification on pretreated corn stover}

Oxygen supply by aeration also enhances the cell growth of $A$. resinae $\mathrm{ZN1}$ thus increases cell mass as biocatalyst 


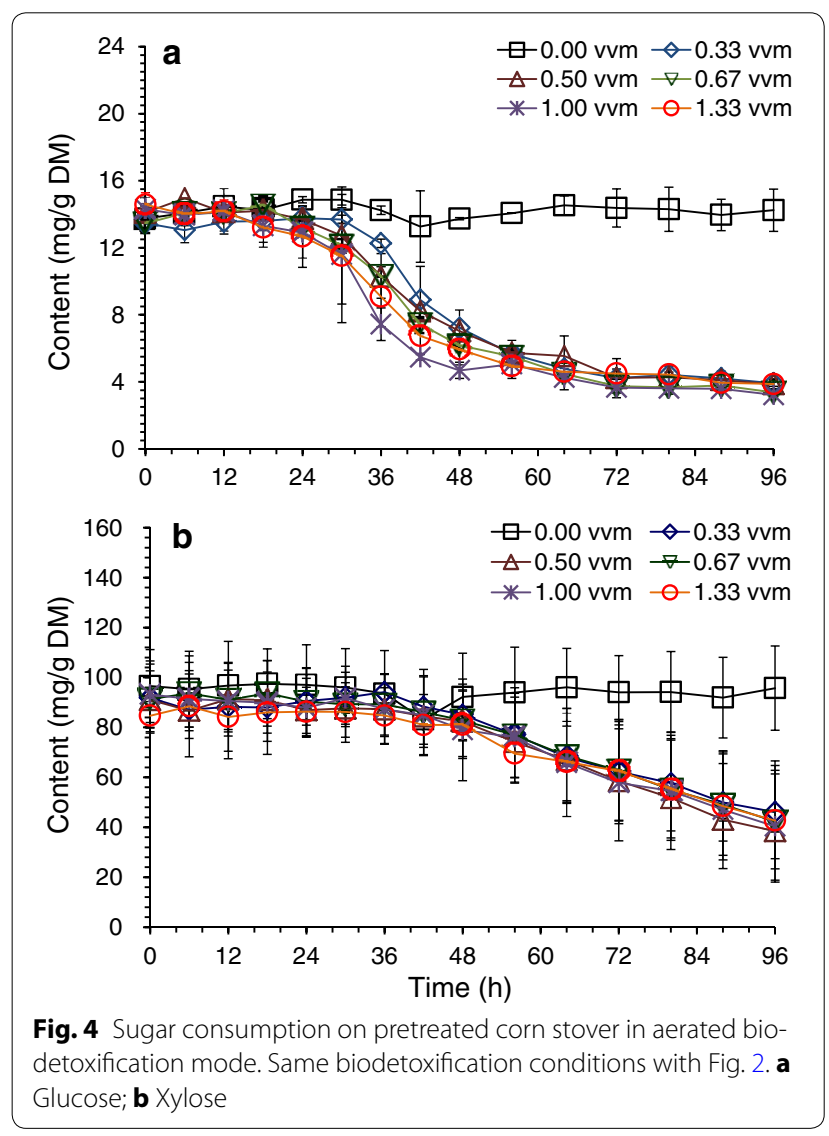

for improvement of inhibitor conversion. In this study, we firstly measured the cell growth of $A$. resinae $\mathrm{ZN} 1$ in the liquid medium by monitoring the change of dry cell weight (DCW) (Fig. 7). At static culture condition, the cells grew to about $0.3 \mathrm{~g} / \mathrm{L}$ when $0.8 \mathrm{~g} / \mathrm{L}$ of furfural was used as sole carbon (Fig. 7a), and to about $2 \mathrm{~g} / \mathrm{L}$ in the medium when $20 \mathrm{~g} / \mathrm{L}$ of glucose (Fig. 7c) or xylose (Fig. 7e) were added to the medium. When the cell culture was moved to the shakers to increase dissolved oxygen in the medium, the conversion period of furfural was reduced by about $36 \mathrm{~h}$ compared to that in the culture in static state (Fig. 7b, d, f). However, the cell growth was still slow during first $60 \mathrm{~h}$ (furfural degradation) and then increased quickly to the similar DCW value $(2 \mathrm{~g} / \mathrm{L})$ to that in the static culture within a much shorter time (from 384 to $144 \mathrm{~h}$ ). These results indicate that the increased dissolved oxygen did not obviously improve the cell growth of $A$. resinae $\mathrm{ZN1}$, but accelerated the furfural conversion.

When the measurement of cell growth on the solid pretreated CS was tested, we found that the routine quantitative methods did not work. Obviously the direct DCW measurement was not suitable because cell mycelia were firmly mixed with solid lignocellulose fibers. On the other hand, the routine glucosamine detection method for fungus mycelia assay [30] and the conservative $\beta$-actin expression detection by real-time fluorescence quantitative polymerase chain reaction [31] were tested, but also did not work. The reason is that pretreatment disrupted the CS cell wall then the glucosamine or $\beta$-actin proteins from CS cells were exposed, and were not able to distinguish from the similar proteins in $A$. resinae $\mathrm{ZN} 1$. As a qualitative alternative method, the direct observation of fungus mycelia and spores using environmental scanning electron microscope (ESEM) was applied (Fig. 8). A. resinae $\mathrm{ZN1}$ fungus on potato dextrose agar slant (PDA slant) was used as the positive control (Fig. 8a) and the CS solids without $A$. resinae inoculation were used as the negative control (Fig. 8b). After the inoculation of A. resinae cells, cell mycelia were observed on CS solids (Fig. 8c). The mycelium numbers were not in an observable increase after aerated detoxification for $18 \mathrm{~h}$ (Fig. 8d). Limited increase of mycelia was observed when aerated biodetoxification lasted for $36 \mathrm{~h}$ (Fig. 8e). Only when the biodetoxification extended to $96 \mathrm{~h}$, the massive growth of mycelia was observed, which was similar to the seed of $A$. resinae $\mathrm{ZN1}$ on the PDA slant (Fig. 8f). The results suggest that similar to the liquid medium, the cell growth of $A$. resinae $\mathrm{ZN1}$ during inhibitors' degradation was limited even though sufficient oxygen was supplied.

To further evaluate the fungus growth during aerated biodetoxification, biodetoxification was conducted with changing inoculum under aeration condition (Fig. 9). The conversion rate of inhibitors was reduced when the inoculum ratio decreased from 10 to $5 \%$ indicating that the amount of initial strain inoculated into the pretreated CS had a significant impact on the biodetoxification. Also the results showed that the growth during the inhibitor degradation was slow because no more strains could help to improve the efficiency of inhibitor degradation at a low initial strain. These results go well with the phenomenon observed by ESEM (Fig. 8). There is no further increase when inoculum ratio of $A$. resinae spores increased from 10 to $20 \%$ (Fig. 9). Perhaps $10 \%$ inoculum ratio was the minimum for cell consortium growth with the current pretreatment severity but the further increase of spores was not helpful to accelerating the biodetoxification rate.

Since the cell growth of $A$. resinae strain was not improved by aeration, the accelerated biodetoxification rate should come from the enhanced inhibitor metabolism of the same amount of cell mass. From the metabolic analysis of furfural and HMF in A. resinae (Ran et al., 2014), the reductive cofactors such as nicotinamide adenine dinucleotide or nicotinamide adenine dinucleotide phosphate were generated when furfuryl alcohol was converted to furfural and then to furoic acid. The increased cofactor supply could further support 


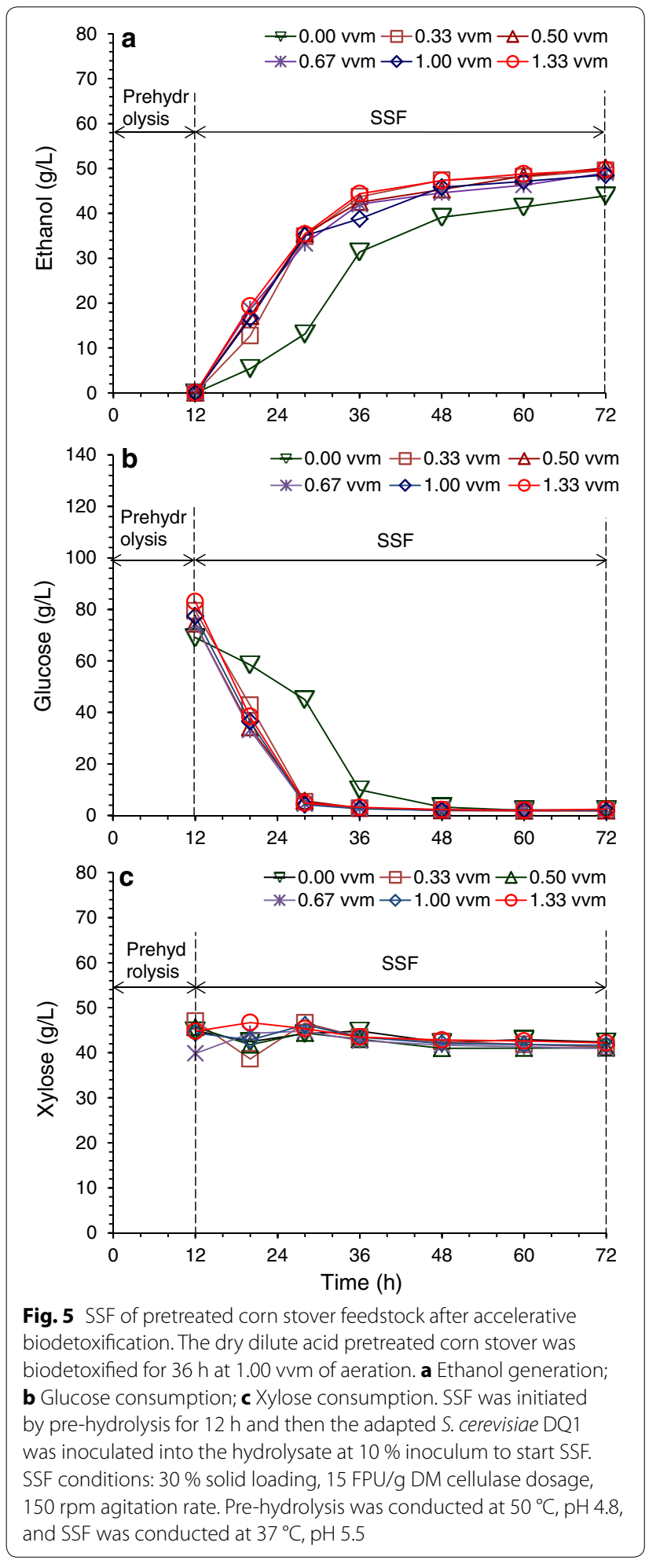

the bioconversion of HMF $[11,16]$. Acetic acid could be directly converted to acetyl-CoA with the aid of ATP [32] and then enter the TCA cycle. The fast degradation of acetic acid and no metabolites detected suggested that the metabolism of acetic acid in A. resinae ZN1 was similar to that described by Wei et al. [32]. The accelerated conversion of furfural, furfuryl alcohol, and furoic acid provide the NADH or NADPH which could be converted to ATP for the fast degradation of acetic acid. The metabolic pathway of the three main phenolic compounds was similar to furfural and HMF, where the phenolic aldehydes were converted to their alcohol form and acid form. The formation of furan acids could provide reducing power for phenolic compound degradation [33]. In this study, the accelerated conversion of furfuryl alcohol to furoic acid by aeration could have played an initiating power for the overall acceleration of biodetoxification of all inhibitor compounds. However, to confirm the hypothesis, the quantitative assay of NADH or NADPH in $A$. resinae cells is needed under the condition of clear separation of fungus mycelia from lignocellulose fibers in the future studies.

\section{Conclusions}

The accelerated biodetoxification realized by aeration and well mixing greatly shortened the period of inhibitor removal from pretreated CS by A. resinae ZN1 and ensured the sequent ethanol production. The retention of xylose component generated during pretreatment made the process more efficient and economic. The improvement of the conversion NAD and NADH involved in the metabolism of furan compounds under aeration condition enhances the biodetoxification rather than the growth of $A$. resinae $\mathrm{ZN1}$. The accelerated biodetoxification provides a practical solution to increase the efficiency of ethanol production from lignocellulosic materials.

\section{Methods}

\section{Raw materials and pretreatment}

Corn stover (CS) was harvested in fall 2012 from Dancheng, Henan, China. Corn stover was washed to remove field dirts, sand, and metals then dried and sealed in plastic bags until use. The virgin CS contained $36.18 \%$ of cellulose and $19.83 \%$ of xylan determined by the method of two-step acid hydrolysis described as national renewable energy laboratory protocols $[34,35]$.

The dry dilute acid pretreatment at about $70 \%$ solid loading was carried out in a helical ribbon impellerdriven reactor by co-currently feeding of dilute sulfuric acid solution and CS as described by Zhang et al. [36] and $\mathrm{He}$ et al. [37]. The pretreatment condition was fixed at $175{ }^{\circ} \mathrm{C}$ for 5 min at $2.5 \%$ sulfuric acid usage per dry CS. The pretreated CS obtained from the reactor maintained the solid state with about $45 \%$ solid content. The pretreated CS contained $40.14 \%$ of cellulose, $3.08 \%$ of 

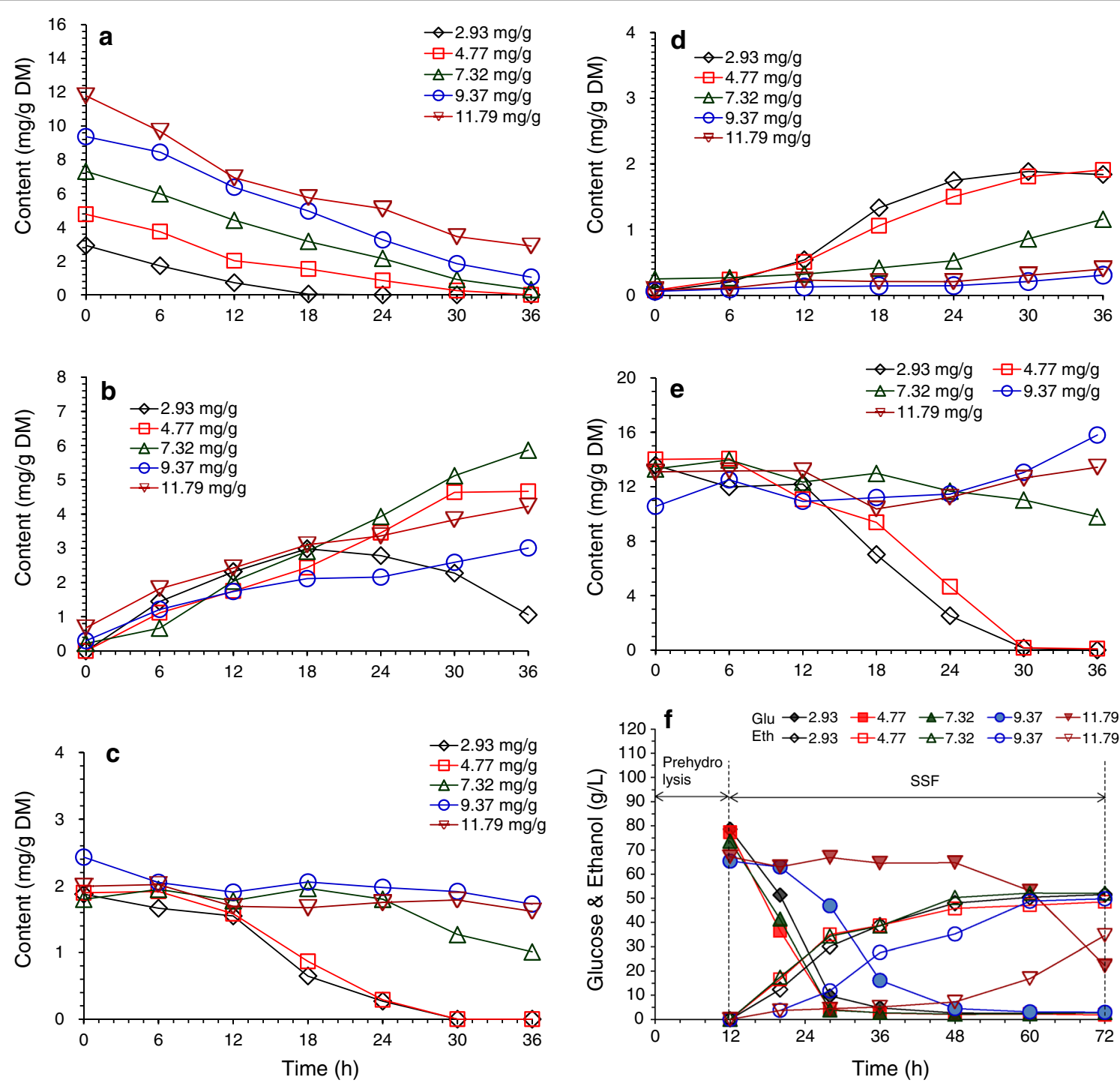

Fig. 6 Accelerative biodetoxification of pretreated corn stover feedstock at changing furfural content. a Furfural; b Furfuryl alcohol; $\mathbf{c} H M F ; \mathbf{d} H M F$ alcohol; e Acetic acid; $\mathbf{f S S F}$ at $30 \%$ solids loading and $15 \mathrm{FPU} / \mathrm{g}$ DM cellulase dosage. Furfural content in the pretreated corn stover was adjusted to $2.93,4.98,7.32,9.37$, and $11.79 \mathrm{mg} / \mathrm{g}$ DM. Biodetoxification conditions: $28^{\circ} \mathrm{C}, \mathrm{pH} \mathrm{5.5,1.00} \mathrm{WVM}$ aeration rate. Agitation was switched on before taking samples

xylan, $13.45 \mathrm{mg} / \mathrm{g} \mathrm{DM}$ of glucose, $97.78 \mathrm{mg} / \mathrm{g} \mathrm{DM}$ of xylose, $13.28 \mathrm{mg} / \mathrm{g}$ DM of acetic acid, $5.34 \mathrm{mg} / \mathrm{g} \mathrm{DM}$ of furfural, $2.14 \mathrm{mg} / \mathrm{g}$ DM of HMF, $2.26 \mathrm{mg} / \mathrm{g}$ DM of vanillin, $0.24 \mathrm{mg} / \mathrm{g} \mathrm{DM}$ of 4-HBA, $0.92 \mathrm{mg} / \mathrm{g} \mathrm{DM}$ of syringaldehyde determined by the method of two-step acid hydrolysis as described in NREL protocols [34, 35].

\section{Enzyme and reagents}

The cellulase enzyme Youtell No.6 was purchased from Hunan Youtell Biochemical Co., Yueyang, Hunan, China. The filter paper and cellobiase activity of the enzyme were $135 \mathrm{FPU} / \mathrm{g}$ and $344 \mathrm{CBU} / \mathrm{g}$ measured by the methods described by NREL LAP-006 [38] and Ghose [39], respectively. The protein content in the cellulase was $90 \mathrm{mg} / \mathrm{g}$ measured by Bradford method. Chemical reagents used in the experiments were purchased from Shanghai Lingfeng Reagents Co. and Shanghai Demo Medical Tech Co., Shanghai, China.

\section{Strains and culture}

The biodetoxification strain $A$. resinae ZN1 (CGMCC 7452, Chinese General Microorganisms Collection Center, Beijing, China) was used for removal of inhibitors from pretreated CS materials. Spore suspension of 


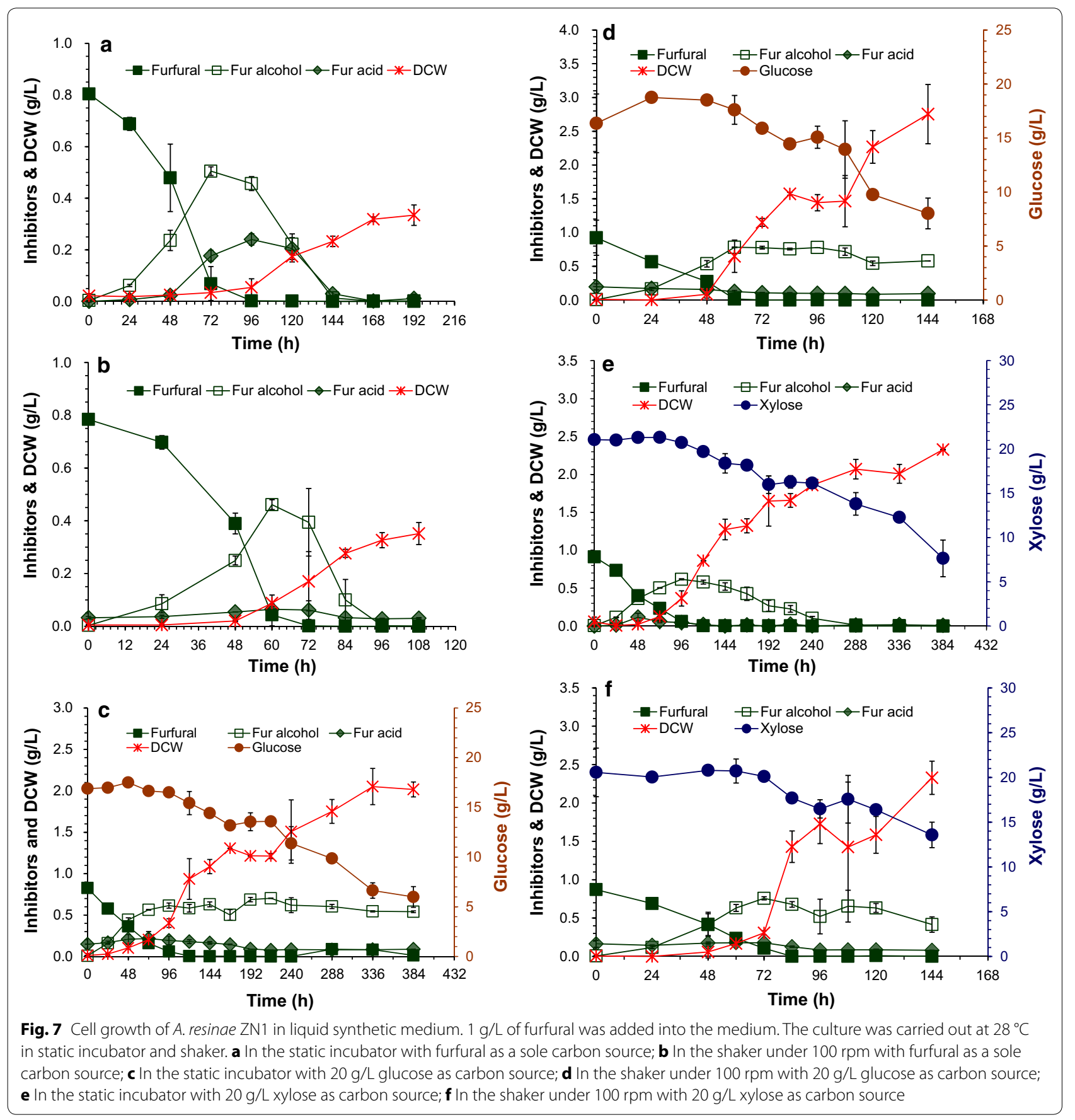

A. resinae $\mathrm{ZN1}$ was inoculated into the liquid medium containing $1 \mathrm{~g} / \mathrm{L}$ of furfural, $2 \mathrm{~g} / \mathrm{L}$ of $\mathrm{KH}_{2} \mathrm{PO}_{4}, 1 \mathrm{~g} / \mathrm{L}$ of $\left(\mathrm{NH}_{4}\right)_{2} \mathrm{SO}_{4}, 1 \mathrm{~g} / \mathrm{L}$ of $\mathrm{MgSO}_{4} \cdot 7 \mathrm{H}_{2} \mathrm{O}, 1 \mathrm{~g} / \mathrm{L}$ of yeast extracts, $0.5 \mathrm{~g} / \mathrm{L}$ of $\mathrm{CaCl}_{2}$, and $20 \mathrm{~g} / \mathrm{L}$ of glucose or xylose, then cultured in the incubator or shaker at $28^{\circ} \mathrm{C}$, and constant $\mathrm{pH}$ value of 5.0 for 16 days.

The ethanol fermenting strain Saccharomyces cerevisiae DQ1 (CGMCC 2528, Chinese General Microorganisms Collection Center, Beijing, China) was used for ethanol fermentation. S. cerevisiae DQ1 was evolutionarily adapted for 65 days in freshly pretreated CS hydrolysate and stored at $-80{ }^{\circ} \mathrm{C}$ till use [25]. Then the yeast was first cultured in the synthetic medium containing $20 \mathrm{~g} / \mathrm{L}$ of glucose, $2 \mathrm{~g} / \mathrm{L}$ of $\mathrm{KH}_{2} \mathrm{PO}_{4}, 1 \mathrm{~g} / \mathrm{L}$ of $\left(\mathrm{NH}_{4}\right)_{2} \mathrm{SO}_{4}, 1 \mathrm{~g} / \mathrm{L}$ of $\mathrm{MgSO}_{4} \cdot 7 \mathrm{H}_{2} \mathrm{O}, 1 \mathrm{~g} / \mathrm{L}$ of yeast extracts, and then cultured in the hydrolysate of CS as seed culture according to the procedure as described in Chu et al. [40]. 

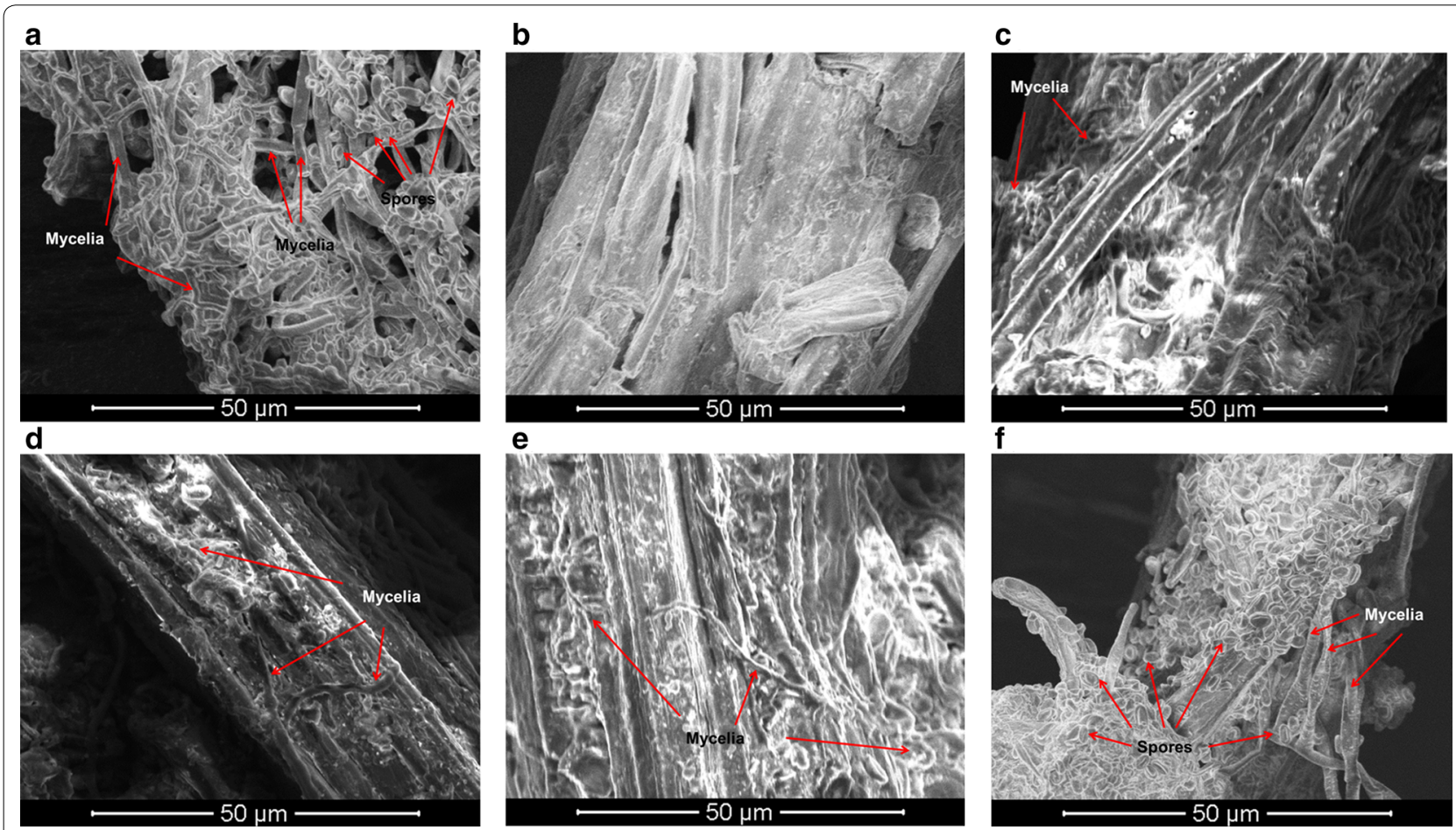

Fig. 8 Cell growth of $A$. resinae ZN1 on pretreated corn stover during aerated biodetoxification by Environmental Scanning Electric Microscope (ESEM). a A. resinae ZN1 growing on PDA slant; $\mathbf{b}$ Corn stover without inoculum of $A$. resinae ZN1; c Corn stover inoculated by $A$. resinae ZN1 at 0 h; $\mathbf{d}$ Corn stover inoculated for $18 \mathrm{~h}$; e Corn stover inoculated for $36 \mathrm{~h}$; $\mathbf{f}$ Corn stover inoculated for $96 \mathrm{~h}$

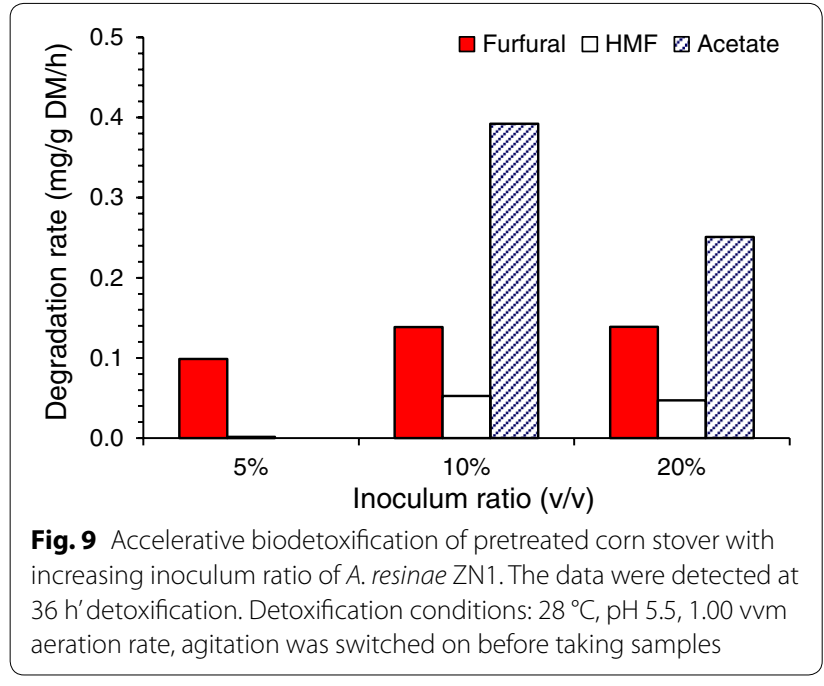

\section{Solid state biodetoxification}

The pretreated CS was first neutralized by $20 \%(w / w)$ $\mathrm{Ca}(\mathrm{OH})_{2}$ slurry to $\mathrm{pH} 5.5$ and then inoculated by $A$. resinae ZN1 in the form of mycelia on CS solids at $10 \%$ inoculum by weight. The process was carried out in a sealed plastic box without aeration. The mixture of inoculum and pretreated CS occupied $1 / 4$ volume of the box. No additional nutrients were supplied on the pretreated CS material. The detoxified CS was collected as feedstock for consequent SSF. Five grams of sample was withdrawn periodically from the culture and mixed with $50 \mathrm{~g}$ water under $30^{\circ} \mathrm{C}, 180 \mathrm{rpm}$ for $1 \mathrm{~h}$. The supernatant of the mixture was collected for inhibitors and sugars' analysis.

Fast biodetoxification of pretreated CS was conducted in $5 \mathrm{~L}$ bioreactor equipped with helical ribbon impeller as described by Zhang et al. [42]. $900 \mathrm{~g}$ pretreated CS was loaded in the reactor with $10 \%(w / w)$ inoculum of seed culture. Biodetoxification was then carried out under different aeration rate of $0,0.33,0.50,0.67,1.00$, and $1.33 \mathrm{vvm}$. The aeration rate (vvm) was defined as the air flow rate $(\mathrm{L} / \mathrm{min})$ per liter of loosely packed pretreated CS material in the bioreactor. The CS material was mixed slowly for $90 \mathrm{~s}$ prior to the samples withdrawing and the rest time of biodetoxification was still carried out in a solid state culture.

\section{Simultaneous saccharification and ethanol fermentation (SSF)}

Simultaneous saccharification and ethanol fermentation using the detoxified CS as feedstock was carried out at $30 \%(w / w)$ solid loading, 15 FPU/g DM cellulase dosage, 
$150 \mathrm{rpm}$, and $\mathrm{pH} 5.5$ in the $5 \mathrm{~L}$ helical ribbon bioreactor [41]. $10 \%$ inoculum of the yeast seed culture and the nutrients $\left(2 \mathrm{~g} / \mathrm{L}\right.$ of $\mathrm{KH}_{2} \mathrm{PO}_{4}, 1 \mathrm{~g} / \mathrm{L}$ of $\left(\mathrm{NH}_{4}\right)_{2} \mathrm{SO}_{4}, 1 \mathrm{~g} / \mathrm{L}$ of $\mathrm{MgSO}_{4} \cdot 7 \mathrm{H}_{2} \mathrm{O}, 1 \mathrm{~g} / \mathrm{L}$ of yeast extract) were added into the slurry after $12 \mathrm{~h}$ ' pre-hydrolysis. Temperature was controlled at $50{ }^{\circ} \mathrm{C}$ during $12 \mathrm{~h}$ ' pre-hydrolysis and $37{ }^{\circ} \mathrm{C}$ during SSF. When the rapid detoxification was carried out in the $5 \mathrm{~L}$ helical ribbon bioreactor, the following SSF was then initiated in the same reactor. The ethanol yield was calculated using the modified equation for the ethanol fermentation at high solids loading described in [42]. The equation was described as below: Ethanol yield $(\%)=\frac{[C] \times W}{976.9-0.804 \times[C]} \times \frac{1}{0.511 \times f \times[\text { biomass }] \times m \times 1.111} \times 100 \%$ where $[C]$ is the concentration of ethanol in the fermentation broth at the end of the SSF $(\mathrm{g} / \mathrm{L}), W$ is total water input into the SSF system $(\mathrm{g}), f$ is the cellulose content in the dry corn stover $(\mathrm{g} / \mathrm{g})$, [biomass] is the dry corn stover loading $(\mathrm{g} / \mathrm{g}), \mathrm{m}$ is total weight of the SSF system at the beginning of the operation, 976.9 is the correction factor, 1.111 is theconversion factor for cellulose to equivalent glucose, 0.511 is the conversion factor for glucose to ethanol based on the stoichiometric biochemistry of yeast.

\section{Fungus growth assay}

Cell growth of $A$. resinae ZN1 in liquid medium was measured by DCW. The culture broth was first filtered and the cell mycelia were dried at $105^{\circ} \mathrm{C}$ for $12 \mathrm{~h}$ till constant weight.

Cell growth of $A$. resinae ZN1 on pretreated CS was qualitatively monitored by ESEM (Quanta 250, FEI Co., USA) with accelerated voltage of $12.5 \mathrm{kV}$. Fungal filamentous mycelia and spores observed from ESEM were used for illustration of fungus growth.

\section{Inhibitors, sugars, and ethanol analysis}

Sugars, organic acids, and ethanol were analyzed on HPLC (LC-20AD, Shimazu, Kyoto, Japan) equipped with a Bio-rad Aminex HPX-87H column (Bio-rad, USA) and RID-10A detector (Shimadzu, Kyoto, Japan). $5 \mathrm{mM}$ $\mathrm{H}_{2} \mathrm{SO}_{4}$ solution was used as flow phase at the flow rate of $0.6 \mathrm{ml} / \mathrm{min}$. Furans were analyzed on HPLC (LC-20AT, Shimazu, Kyoto, Japan) equipped with a YMC-Pack ODS-A column (YMC, Tokyo, Japan) and an SPD-20A UV detector (Shimadzu, Kyoto, Japan).

Furfural and furfuryl alcohol were analyzed using $50 \%$ acetonitrile as flow phase at the flow rate of $1.0 \mathrm{ml} / \mathrm{min}$ at the column temperature of $35{ }^{\circ} \mathrm{C}$ and the detection wavelength of $220 \mathrm{~nm}$. HMF and HMF alcohol were analyzed using the following gradient: the initial flow phase was composed by pure water (pump A) and acetonitrile (pump B) at a ratio of 95 to $5 \%$; first, acetonitrile was increased from 5 to $100 \%$ over $0-15 \mathrm{~min}$; then, acetonitrile was decreased from 100 to $5 \%$ over $15-20 \mathrm{~min}$; finally, acetonitrile was used at $5 \%$ over $20-30 \mathrm{~min}$. Phenolic compounds were analyzed using the following gradient: the initial flow phase was composed by $0.1 \%$ formic acid solution (pump A) and acetonitrile (pump B) at a ratio of 90 to $10 \%$; first the acetonitrile concentration increased to $35 \%$ over $4-5 \mathrm{~min}$ and kept at $35 \%$ over $5-20 \mathrm{~min}$; then the acetonitrile concentration decreased to $10 \%$ over $20-21 \mathrm{~min}$; finally, acetonitrile was used at $10 \%$ over $21-30 \mathrm{~min}$. All samples were filtered through $0.22 \mu \mathrm{m}$ membrane prior to HPLC analysis.

\section{Additional file}

Additional file 1: Figure S1. The detection of furfural volatilization without inoculum under different aeration rate in the $5 \mathrm{~L}$ fermenter. The volatilization of furfural in the pretreated corn stover under different aeration rate without inoculation of $A$. resinae $Z \mathrm{~N} 1$. The conditions were controlled at $28^{\circ} \mathrm{C}, \mathrm{pH} 5.5$. The volatilization was calculated by the ratio of reduced furfural content to the original furfural content.

\section{Abbreviations}

HMF: 5-Hydroxymethylfurfural; HMF alcohol: 2,5-Furandiyldimethanol (5-Hydroxymethylfurfuryl alcohol); HMF acid: 5-Hydroxymethyl-2-furoic acid (5-Hydroxymethylfuroic acid); NADH: nicotinamide adenine dinucleotide (reduced); NADPH: nicotinamide adenine dinucleotide phosphate (reduced); PCR: polymerase chain reaction; ESEM: environmental scanning electron microscope; PDA: potato dextrose agar; NREL: national renewable energy laboratory; LAP: laboratory analytical procedure.

\section{Authors' contributions}

YQH and JB designed the experiment and drafted the manuscript. YQH carried out the experiment. JZ participated in the design of the study and helped to revise the manuscript. JB conceived of the study. All authors read and approved the final manuscript.

\section{Acknowledgements}

This research was supported by the Natural Science Foundation of China (31300070) and the National High-Tech Program of China (2012AA022301/2014AA021901), and the Fundamental Research Funds for the Central Universities of China (WF1514325).

\section{Competing interests}

The authors declare that they have no competing interests.

Received: 7 November 2015 Accepted: 8 January 2016 Published online: 26 January 2016

\section{References}

1. Palmqvist E, Hahn Hagerdal B. Fermentation of lignocellulosic hydrolysates. Bioresour Technol. 2000;74:17-33.

2. Li H, Chen H. Detoxification of steam-exploded corn straw produced by an industrial-scale reactor. Process Biochem. 2008:43:1447-51.

3. Cantarella M, Cantarella L, Gallifuoco A, Spera A, Alfani F. Comparison of different detoxification methods for steam-exploded poplar wood as a substrate for the bioproduction of ethanol in SHF and SSF. Process Biochem. 2004;39:1533-42.

4. Mussatto SI, Roberto IC. Alternatives for detoxification of diluted-acid lignocellulosic hydrolyzates for use in fermentative processes: a review. Bioresour Technol. 2004;93:1-10.

5. Dong HW, Bao J. Biofuel via biodetoxification. Nat Chem Biol. 2010;6:316-8

6. Okuda N, Soneura M, Ninomiya K, Katakura Y, Shioya S. Biological detoxification of waste house wood hydrolysate using 
Ureibacillus thermosphaericus for bioethanol production. J Biosci Bioeng. 2008;106:128-33.

7. Zhang J, Zhu Z, Wang X, Wang N, Wang W, Bao J. Biodetoxification of toxins generated from lignocellulose pretreatment using a newly isolated fungus, Amorphotheca resinae ZN1, and the consequent ethanol fermentation. Biotechnol Biofuels. 2010;3:26.

8. Parawira W, Tekere M. Biotechnological strategies to overcome inhibitors in lignocellulose hydrolysates for ethanol production: review. Crit Rev Biotechnol. 2011;31:20-31.

9. Chandel AK, da Silva SS, Singh OV. Detoxification of lignocellulose hydrolysates: biochemical and metabolic engineering toward White Biotechnology. Bioeng Res. 2013;6:388-401.

10. Wierckx N, Koopman F, Bandounas L, de Winde JH, Ruijssenaars HJ. Isolation and characterization of Cupriavidus basilensis HMF14 for biological removal of inhibitors from lignocellulosic hydrolysate. Microbial Biotechnol. 2010;3:336-43.

11. Koopman F, Wierckx N, de Winde $J \mathrm{H}$, Ruijssenaars HJ. Identification and characterization of the furfural and 5-(hydroxymethyl)furfural degradation pathways of Cupriavidus basilensis HMF14. Proc Natl Acad Sci U S A. 2010;107:4919-24.

12. Zhang D, Ong YL, Li Z, Wu JC. Biological detoxification of furfural and 5-hydroxyl methyl furfural in hydrolysate of oil palm empty fruit bunch by Enterobacter sp. FDS8. Biochem Eng J. 2013;72:77-82.

13. Hunter WJ, Manter DK. Pre-treatment step with Leuconostoc mesenteroides or L. pseudomesenteroides strains removes furfural from Zymomonas mobilis ethanolic fermentation broth. Bioresour Technol. 2014;169:162-8

14. Tsuge Y, Hori Y, Kudou M, Ishii J, Hasunuma T, Kondo A. Detoxification of furfural in Corynebacterium glutamicum under aerobic and anaerobic conditions. Appl Microbiol Biotechnol. 2014;98:8675-83.

15. Choi SY, Gong G, Park HS, Um Y, Sim SJ, Woo HM. Extreme furfural tolerance of a soil bacterium Enterobacter cloacae GGT036. J Biotechnol. 2015;193:11-3.

16. Liu ZL, Slininger PJ, Gorsich SW. Enhanced biotransformation of furfural and hydroxymethylfurfural by newly developed ethanologenic yeast strains. Appl Biochem Biotechnol. 2005;121-124:451-60.

17. Fonseca BG, Moutta RO, Ferraz FO, Vieira ER, Nogueira AS, Baratella BF, Rodrigues LC, Zhang HR, da Silva SS. Biological detoxification of different hemicellulosic hydrolysates using Issatchenkia occidentalis CCTCC M206097 yeast. J Ind Microbiol Biotechnol. 2011;38:199-207.

18. Huang C, Wu H, Smith TJ, Liu Z, Lou WY, Zong M. In vivo detoxification of furfural during lipid production by the oleaginous yeast Trichosporon fermentans. Biotechnol Lett. 2012;34:1637-42.

19. Palmqvist E, Hahn-Hagerdal B, Szengyel Z, Zacchi G, Reczey K. Simultaneous detoxification and enzyme production of hemicellulose hydrolysates obtained after steam pretreatment. Enzyme Microbial Technol. 1997;20:286-93

20. Lopez MJ, Nichols NN, Dien BS, Moreno J, Bothast RJ. Isolation of microorganisms for biological detoxification of lignocellulosic hydrolysates. Appl Microbiol Biotechnol. 2004;64:125-31.

21. Nichols NN, Dien BS, Guisaoo GM, Lopez MJ. Bioabatement to remove inhibitors from biomass-derived sugar hydrolysates. Appl Biochem Biotechnol. 2005;121-124:379-90.

22. Nichols NN, Sharma LN, Mowery RA, Chambliss CK, van Walsum GP, Dien BS, Iten LB. Fungal metabolism of fermentation inhibitors present in corn stover dilute acid hydrolysate. Enzyme Microb Technol. 2008;42:624-30.

23. Saha BC, Nichols NN, Cotta MA. Ethanol production from wheat straw by recombinant Escherichia coli strain FBR5 at high solid loading. Bioresour Technol. 2011:102:10892-7.

24. Yu Y, Feng Y, Xu C, Liu J, Li D. Onsite bio-detoxification of steam-exploded corn stover for cellulosic ethanol production. Bioresour Technol. 2011;102:5123-8.
25. Qureshi AS, Zhang J, Bao J. High ethanol fermentation performance of the dry dilute acid pretreated corn stover by an evolutionarily adapted Saccharomyces cerevisiae strain. Bioresour Technol. 2015;189:399-404.

26. Huang $X$, Wang Y, Liu W, Bao J. Biological removal of inhibitors leads to the improved lipid production in the lipid fermentation of corn stover hydrolysate by Trichosporon cutaneum. Bioresour Technol. 2011;102:9705-9.

27. Zhao K, Qiao Q, Chu D, Gu H, Dao TH, Zhang J, Bao J. Simultaneous saccharification and high titer lactic acid fermentation of corn stover using a newly isolated lactic acid bacterium Pediococcus acidilactici DQ2. Bioresour Technol. 2013;135:481-9.

28. Ran H, Zhang J, Gao Q, Lin Z, Bao J. Analysis of biodegradation performance of furfural and 5-hydroxymethylfurfural by Amorphotheca resinae ZN1. Biotechnol Biofuels. 2014;7:51.

29. Wang X, Gao QQ, Bao J. Transcriptional analysis of Amorphotheca resinae ZN1 on biological degradation of furfural and 5-hydroxymethylfurfural derived from lignocellulose pretreatment. Biotechnol Biofuels. 2015;8:136.

30. Scotti CT, Vergoignan C, Feron G, Durand A. Glucosamine measurement as indirect method for biomass estimation of Cunninghamella elegans grown in solid state cultivation conditions. Biochem Eng J. 2001;7:1-5.

31. Bui XT, Wolff A, Madsen M, Bang DD. Reverse transcriptase real-time PCR for detection and quantification of viable Campylobacter jejuni directly from poultry faecal samples. Res Microbiol. 2012;163:64-72.

32. Wei N, Quarterman J, Kim SR, Cate JH, Jin YS. Enhanced biofuel production through coupled acetic acid and xylose consumption by engineered yeast. Nat commun. 2013:4:2580.

33. Yi X, Gu H, Gao Q, Liu ZL, Bao J. Transcriptome analysis of Zymomonas mobilis ZM4 reveals mechanisms of tolerance and detoxification of phenolic aldehyde inhibitors from lignocellulose pretreatment. Biotechnol Biofuels. 2015;8:153.

34. Sluiter A, Hames B, Ruiz R, Scarlat C, Sluiter J, Templeton D, Crocker D. Determination of structural carbohydrates and lignin in biomass. Laboratory analytical procedure (LAP). Technical Report NREL/TP-510-42618. 2008a; Golden, CO.

35. Sluiter A, Hames B, Ruiz R, Scarlata C, Sluiter J, Templeton D. Determination of sugars, byproducts, and degradation products in liquid fraction process samples. Laboratory analytical procedure (LAP). Technical Report NREL/TP-510-42623. 2008b; Golden, CO.

36. Zhang J, Wang $X, C$ Chu D, He Y, Bao J. Dry pretreatment of lignocellulose with extremely low steam and water usage or bioethanol production. Bioresour Technol. 2011;102:4480-8.

37. He Y, Zhang L, Zhang J, Bao J. Helically agitated mixing in dry dilute acid pretreatment enhances the bioconversion of corn stover into ethanol. Biotechnol Biofuels. 2014;7:1.

38. Adney B, Baker J. Measurement of cellulase activities. NREL/TP-510-42628. 1996; Golden, CO.

39. Ghose TK. Measurement of cellulase activities. Pure Appl Chem. 1987;59:257-68.

40. Chu D, Zhang J, Bao J. Simultaneous Saccharification and ethanol fermentation of corn stover at high temperature and high solids loading by a thermotolerant strain Saccharomyces cerevisiae DQ1. Bioeng Res. 2012;5:1020-6.

41. Zhang J, Bao J. A modified method for calculating practical ethanol yield at high lignocellulosic solids content and high ethanol titer. Bioresour Technol. 2012;116:74-79.

42. Zhang J, Chu D, Huang J, Yu Z, Dai G, Bao J. Simultaneous saccharification and ethanol fermentation at high corn stover solids loading in a helical stirring bioreactor. Biotechnol Bioeng. 2010;105:718-28. 